\title{
Optimization of Preventive Maintenance and Replacement Strategies for Nonrenewing Two-Dimensional Warranty Products Experiencing Degradation and External Shocks
}

\author{
Liying wang $\mathbb{D}$ and Yushuang Song $\mathbb{D}$ \\ Department of Mathematics \& Physics, Shijiazhuang Tiedao Institute, Shijiazhuang 050043, China \\ Correspondence should be addressed to Liying wang; wly_sjz@sohu.com
}

Received 3 October 2021; Revised 16 December 2021; Accepted 10 January 2022; Published 16 February 2022

Academic Editor: Debiao Meng

Copyright (C) 2022 Liying wang and Yushuang Song. This is an open access article distributed under the Creative Commons Attribution License, which permits unrestricted use, distribution, and reproduction in any medium, provided the original work is properly cited.

\begin{abstract}
"Vehicle damage insurance" in China, "Protection Plus Mobile Elite" launched by Samsung, "iPhone Apple Care +" offered by Apple, and so on are special warranty services aiming at external shocks. These warranty terms, named accident insurance, exist widely in the marketplace. Considering the effect of external shocks on degradation, a two-dimensional preventive maintenance and replacement strategy for products, sold with a nonrenewing and two-dimensional rectangle warranty service, is proposed in this paper. Under this strategy, preventive maintenance actions are scheduled based on units of age or usage, which occurs first. There is a reduction in the intensity function after a preventive maintenance action. Each shock before the Nth shock causes a failure of the product or an increase in product failure rate. The product is replaced by a new one on the Nth shock if it survives the $N-1$ shocks. From the view of manufacturers, the mean warranty servicing cost over the whole warranty region is obtained by using the renewal theory. Based on direct numerical Riemann-Stieltjes integration, an approximation algorithm of the cost is also given. The mean cost is minimized by the optimization of preventive maintenance interval and the number of shocks $N$. A numerical example is given to illustrate the feasibility of the proposed strategy. The effects of maintenance cost, the arrival rate of the shocks, and other model parameters on the optimal strategy are also investigated numerically.
\end{abstract}

\section{Introduction}

Due to the rapid technological development and fierce competition in the marketplace, it is crucial for manufacturers to make scientific and reasonable decisions on maintenance strategies. Modeling and optimization of corrective maintenance $(\mathrm{CM})$, preventive maintenance (PM), and both of them have been carried out in one-dimensional and two-dimensional warranty services [1].

In the decision-making analysis of one-dimensional warranty policies, combinations of minimal maintenance and replacements, the preventive maintenance intervals, the level of preventive maintenance $[2,3]$, and the length of the residual warranty period [4] are optimized separately or jointly to minimize the expected warranty servicing cost or cost rate over the whole warranty coverage. Multiphase warranty models, in which different repair strategies are performed, have been proposed [5,6]. Recently, warranty policies for degrading products have been proposed. Under the assumption that the failure time of a deteriorating product depends both on its age and a stationary Wiener process, Zheng and Zhou [7] analyzed the warranty servicing costs of three preventive maintenance policies (no inspection, continuous inspection, and periodic inspection) in the Markov decision process framework. Cha et al. [8] focused on the product from a heterogeneous population and discussed the inspection and replacement policies during its warranty period. Li et al. [9] proposed three types of warranty policy-free replacement for deteriorating products with random failure threshold.

A two-dimensional warranty policy is characterized by a region in a two-dimensional plane with one dimension 
representing time and the other representing usage. Wang and Xie [10] gave a comprehensive review on the decisionmaking analysis of two-dimensional warranty policies. On the premise of ensuring the expected availability greater than a preset value, Cheng et al. [11] discussed a warranty strategy combining the imperfect preventive maintenance and minimal repairs. Wang and $\mathrm{Su}$ [12] proposed a two-dimensional (2D) PM strategy for products sold with twodimensional warranty service. Under the 2D PM strategy, the product is maintained preventively every $K$ units of age or $L$ units of usage, whichever occurs first. Su and Wang [13] extended the 2D PM strategy to a two-stage preventive maintenance optimization problem by taking into account the moments that customers purchase two-dimensional extended warranty. Huang et al. [14] proposed a customized two-dimensional extended warranty with preventive maintenance. Preventive maintenance optimization models considering customer satisfaction were investigated by Wang et al. [15]. To meet availability requirements of complex equipment, Su and Cheng [16] investigated an availability-based warranty policy. Under the policy, the manufacturer guarantees a negotiated availability level of products during the warranty period. Wang et al. [17] studied the impact of customer unpunctuality and the shape of failure rate function on the optimization of PM policy. From the view of manufacturers, the coping strategies were given. The aforementioned decision-making research on warranty strategies has been carried out under the assumption that products are only subject to degradation process.

However, most products are subject to degradation and random shocks simultaneously, and a great deal of models considering both of them has been proposed [18-21]. Wiener process [22] and Gamma process [23] are the most commonly used to model products' degradation. Poisson process is proved to be appropriate for describing the arrival of external shocks. Under the assumption of independence [24], unilateral effect [18, 25-28], and mutual dependence $[29,30]$ between degradation and shock process, reliability analysis of those products has been made.

Warranty services aiming at external shocks exist widely in marketplace. Some mobile phone manufacturers offer mobile phone accident insurance such as "Protection Plus Mobile Elite" launched by Samsung, "iPhone Apple Care +" offered by Apple, and so on. Similar services are also provided by well-known domestic mobile phone manufacturers, Huawei and Xiaomi. In China, vehicle damage insurance, a major automobile insurance, covers the loss of insured vehicles caused by external shocks such as collision, overturning, falling, collapse, and so on. There are similar insurance items in Germany. Another two factors, the type of vehicles and the type of drivers, need to be considered.

However, a few studies have considered the effect of external shocks on warranty decision-making. To our knowledge, Wang et al. [17] is the most closely related to our work. Wang et al. [17] proposed a performance-based warranty for products subject to competing hard and soft failures. Under the policy, the manufacturer not only provides free repair or replacement of any defect but also guarantees the minimum performance level throughout the warranty period. Considering the effect of external shocks on products, a 2D PM and replacement strategy is proposed in this paper. The mean cost over the warranty region is minimized by the optimization of the PM interval or the joint optimization of the PM interval and the number of shocks before replacing. Besides focusing on a performancebased warranty, the work of Wang et al. [17] differs from ours in two main aspects. (1) The products in their work exhibit two competing failure modes, hard and soft failures. Whereas, the products in our work are subject to two kinds of hard failures due to loss of functionality, such as product defects, corrosion, fatigue fracture, and external shocks. (2) In their work, if a hard failure or a soft failure occurs within the warranty period, the failed unit will be replaced with a new and identical one. Whereas, in our work, the product fails with a certain probability on each shock and is replaced after the failure. Furthermore, periodic preventive maintenance policies are adopted and minimal repair actions are performed on failures between PM actions. The 2D PM strategy adopted in this paper is the same as that of Wang and $\mathrm{Su}$ [12], whereas the effect of external shocks is not considered in their paper.

The integral equation that the mean warranty servicing cost satisfies is obtained by using the renewal theory. It is shown that the mean cost exhibits increasing tendency when the cost parameters, the arrival rate of shocks, and product failure probability on shocks increase, respectively, whereas it decreases when the reduction in the intensity function after a PM action increases. The impact of the increase of the product failure rate on shocks and the replacement cost on the optimal PM interval is insignificant. Furthermore, the optimal 2D PM interval decreases with the increase of per minimal repair cost and the reduction in the intensity function after a PM action and increases with the increase of the cost of per PM and the arrival rate of shocks.

The reminder of this paper is organized as follows. Section 2 provides the modeling assumptions and notations. Section 3 focuses on the analysis of warranty servicing cost and its numerical integration approximation. In Section 4, a numerical example is provided to demonstrate the proposed 2D PM and replacement strategy. Finally, Section 5 concludes this paper.

We shall use the following notations:

$W$ : the age limit of the two-dimensional rectangle warranty region

$U$ : the usage limit of the two-dimensional rectangle warranty region

$K, L:$ the age and usage interval of the 2D PM

$N$ : the number of shocks before the replacement

$1-p$ : the probability of failure on a shock

$\lambda$ : the arrival rate of the shock

$\lambda_{s}$ : the increase in intensity function on a shock

$\lambda_{p}$ : the reduction of intensity function after a PM action

$N(t)$ : the number of shocks over $(0, t]$

$T_{j}$ : the arrival time of $j$ th shock $(j=1,2, \ldots)$ 
$A_{0}(t)$ : the mean warranty servicing cost over $(0, t)$ in the case that no shock occurs

$B_{i}(t)$ : the mean total warranty cost over $(0, t)$, given the number of shocks over $(0, t)$ in the case that at least one shock occurs and the product is not replaced $(i=1,2, \Lambda, N-1)$

$C_{k}(t)$ : the mean total warranty cost over $(0, t)$, given the number of shocks on the first renew over $(0, t)$ in the case that at least one shock occurs and the product is replaced $(k=1,2, \ldots, N)$

$H(t)$ : the mean total warranty cost over $(0, t)$

$C(N, K, L)$ : the total mean warranty servicing cost over the two-dimensional rectangle warranty region

$C_{r}$ : average cost per replacement

$C_{m}$ : average cost per minimal repair

$C_{p}$ : average cost per PM

\section{Modeling Assumptions}

We first present some modeling assumptions for the model building purpose.

(1) Suppose the product is sold with a two-dimensional rectangle warranty region whose age and usage limits of the region are $W$ and $U$, respectively, that is, the warranty term would be terminated when the age reaches $W$ or the total usage reaches $U$, whichever occurs first. All failures during the warranty coverage are statistically independent.

(2) A periodic two-dimensional preventive maintenance strategy is adopted over the warranty region $(0, W] \times t(0, U]$. That is, $\mathrm{PM}$ activities are scheduled every $K$ units of age or $L$ units of usage, whichever occurs first (see [12]). After a preventive maintenance action, there is a reduction of $\lambda_{p}\left(\lambda_{p}>0\right)$ in the intensity function of the product. Each failure occurs between two successive PM activities is rectified by minimal repair.

(3) The product is affected by the external shocks and customers take out an insurance for the product. According to terms of the insurance, the manufacturer bears the cost of external shocks over the rectangle warranty region. Suppose that shocks arrive in accordance with a homogenous Poisson process with rate $\lambda, \lambda>0$. When the $i$ th $(i \leq N-1)$ shock arrives, the product either fails with probability $1-p$ and is replaced by a new and identical one, or the intensity function of the product increases by $\lambda_{s}$ with probability $p$ and no maintenance activities are performed. The product is replaced on the $N$ th shock. After replacements, the warranty service is the same to a new one, but the warranty region is not renewed (referred as "nonrenewing" warranty [1].

(4) Marginal approach is used in this paper to model the failure process of the product $[31,32]$. Assuming that the usage rate of the product $R$ is a nonnegative random variable with a known distribution function $G(r), 0 \leq r<\infty$. Conditional on $R=r$, the total usage $u$ of a product at age $t$ is given by $u=r t$ and the conditional intensity function form is given by $\lambda(t \mid r)=\theta_{0}+\theta_{1} r+\left(\theta_{2}+\theta_{3} r\right) t$, with parameters $\theta_{i}>0(i=1,2,3)[12]$.

(5) The times of replacements or repairs are small relative mean time failure. They are ignored and treated as instantaneous.

Most assumptions aforementioned can be justified either by industrial practice or literature. Usually, the effects of PM actions can be modeled through a reduction in the intensity function or in the age [33]. We used the first one in Assumption (2). In the literature, the shock magnitude is modeled by a random variable and the product fails once the size of a single shock (known as "extreme shock model" [34]) or the accumulation of random shocks (known as "cumulative shock model" [35]) exceeds the corresponding thresholds. The setting of failure probability $p$ on a shock and the maximal number of shocks before replacement, $N$, in Assumption (4) matches with extreme and cumulative shock models, respectively.

\section{Analysis of Shock Arrival and Warranty Servicing Cost}

The cost over the warranty region is interest to manufacturers. It is also an important factor for pricing and accident insurance of the product. The cost is a random variable because it depends on numbers of PM, minor repairs, and shocks. In this section, we will derive the mean cost for the strategy mentioned earlier.

3.1. The Arrival Time Distributions of Shocks. Let $T_{j}(j=1,2, \ldots)$ denote the arrival time of $j$ th shock. Given $N(t)=n$, then the joint probability density function of $T_{1}, T_{2}, \ldots, T_{n}[36]$ is

$f_{(1)(2) \ldots(n)}\left(t_{1}, t_{2}, \ldots, t_{n} \mid N(t)=n\right)=\frac{n !}{t^{n}}, 0<t_{1}<\cdots<t_{n}<t$.

Given $N(t)=n$, we will derive the joint probability density function of $T_{1}, T_{2}, \cdots, T_{j}$, $f_{(1)(2) \ldots(j)}\left(t_{1}, t_{2}, \ldots, t_{j} \mid N(t)=n\right)(j=1,2, \cdots n-1)$, using the mathematical induction, in the following. Integrating (1) with respect $t_{n}$, we can conclude that the joint probability density function of $T_{1}, T_{2}, \ldots, T_{n-1}$, given $N(t)=n$, is 


$$
\begin{aligned}
f_{(1)(2) \ldots(n-1)}\left(t_{1}, t_{2}, \ldots, t_{n-1} \mid N(t)=n\right) & =\int_{-\infty}^{+\infty} f_{(1)(2) \ldots(n)}\left(t_{1}, t_{2}, \ldots, t_{n} \mid N(t)=n\right) d t_{n} \\
& =\int_{t_{n-1}}^{t} \frac{n !}{t^{n}} d t_{n}=\frac{n !}{t^{n}}\left(t-t_{n-1}\right), 0<t_{1}<\cdots<t_{n-1}<t .
\end{aligned}
$$

Suppose that the joint probability density function of $T_{1}, T_{2}, \ldots, T_{j+1}$, given $N(t)=n$, is

$$
\begin{aligned}
& f_{(1)(2) \ldots(j+1)}\left(t_{1}, t_{2}, \ldots, t_{j+1} \mid N(t)=n\right) \\
& \quad=\frac{n !}{t^{n}} \frac{\left(t-t_{j+1}\right)^{n-(j+1)}}{(n-(j+1)) !}, 0<t_{1}<\cdots<t_{j+1}<t .
\end{aligned}
$$

Integrating equation (3) with respect $t_{j+1}$, we have the joint probability density function of $T_{1}, T_{2}, \ldots, T_{j}$, given $N(t)=n$ :

$$
\begin{aligned}
f_{(1)(2) \ldots(j)}\left(t_{1}, t_{2}, \cdots, t_{j} \mid N(t)=n\right) & =\int_{-\infty}^{+\infty} f_{(1)(2) \ldots(j+1)}\left(t_{1}, t_{2}, \ldots, t_{j+1} \mid N(t)=n\right) \mathrm{d} t_{j+1} \\
& =\int_{t_{j}}^{t} \frac{n !}{t^{n}} \frac{\left(t-t_{j+1}\right)^{n-(j+1)}}{(n-(j+1)) !} \mathrm{d} t_{j+1}=\frac{n !}{t^{n}} \frac{\left(t-t_{j}\right)^{n-j}}{(n-j) !}
\end{aligned}
$$

where $0<t_{1}<\cdots<t_{j}<t$. By the mathematical induction, the joint probability density function of $T_{1}, T_{2}, \cdots, T_{j}(j=1,2, \ldots, n-1)$, given $N(t)=n$, is

$$
\begin{aligned}
& f_{(1)(2) \ldots(j)}\left(t_{1}, t_{2, \ldots} t_{j} \mid N(t)=n\right) \\
& \quad=\frac{n !}{t^{n}} \frac{\left(t-t_{j}\right)^{n-j}}{(n-j) !}, 0<t_{1}<\cdots<t_{j}<t .
\end{aligned}
$$

From the property of the joint probability density function, the probability density function of $T_{k}(k=1,2, \ldots, n)$, given $N(t)=n$, is

$$
\begin{aligned}
f_{(k)}\left(t_{k}\right) & =\int_{0}^{t_{k}} \cdots \int_{0}^{t_{2}} f_{(1)(2) \ldots(k)}\left(t_{1}, t_{2}, \ldots, t_{k}\right) \mathrm{d} t_{1} \cdots \mathrm{d} t_{k-1} \\
& =\frac{n !}{(n-k)(k-1) !}\left(\frac{t_{k}}{t}\right)^{k-1}\left(\frac{t-t_{k}}{t}\right) \frac{1}{t}, 0<t_{k}<t .
\end{aligned}
$$

3.2. Analysis of the Warranty Servicing Cost. To obtain the warranty servicing cost, let $\eta=(U / W)$ and $\eta_{1}=(L / K)$. Considering various orderings between $\eta_{1}$ and $\eta$, two cases, $\eta_{1}<\eta$ and $\eta_{1} \geq \eta$, are needed to be investigated.

For the case of $\eta_{1}<\eta$, three subcases are considered, i.e., $r<\eta_{1}, \eta_{1} \leq r<\eta$, and $r \geq \eta$, as shown in Figure 1. For subcase $r<\eta_{1}$, the warranty period ceases when the age reaches $W$. The usage corresponding to $W$ is $r W$. Under the proposed 2D PM strategy, PM activities are scheduled every $K$ units of age. For subcase $\eta_{1} \leq r<\eta$, the warranty ceases when the age reaches $W$ and the interval of PM activities is $L$ units of usage (that is, $L / r$ units of age). For subcase $r \geq \eta$, the warranty ceases when the usage reaches
$U$, the corresponding age is $U / r$, and the interval of PM activities is also $L$ units of usage. Similar analysis can be done for the case of $\eta_{1} \geq \eta$.

For convenience of expression, let $Y$ be the interval of PM activities and $T$ be the time instant that the two-dimensional rectangle warranty expires; then,

$$
\begin{aligned}
& Y= \begin{cases}K, & r<\eta_{1}, \\
\frac{L}{r}, & r \geq \eta_{1},\end{cases} \\
& T= \begin{cases}W, & r<\eta, \\
\frac{U}{r}, & r \geq \eta .\end{cases}
\end{aligned}
$$

Let $H(t)$ denote the mean total warranty servicing cost over $(0, t)(0<t \leq W)$. We are interested in the renewal equation in term of $H(t)$. Considering various numbers of shocks over $(0, t)$ and their effects on the product, we need to investigate three cases: no shock occurs, at least one shock occur and the product is not replaced, at least one shock occur and the product is replaced. Denote them as Cases 1, 2, 3 , respectively.

(1) Case 1. The probability for Case 1 is $e^{-\lambda t}$. For this case, periodic PM and minor repair activities are performed over $(0, t)$.

Let $l$ be the number of PM activities over $(0, t)$; then,

$$
l=\max \{j \mid j Y \leq t, j \geq 0\} .
$$

The mean number of minor repair activities over $(0, t)$ : 


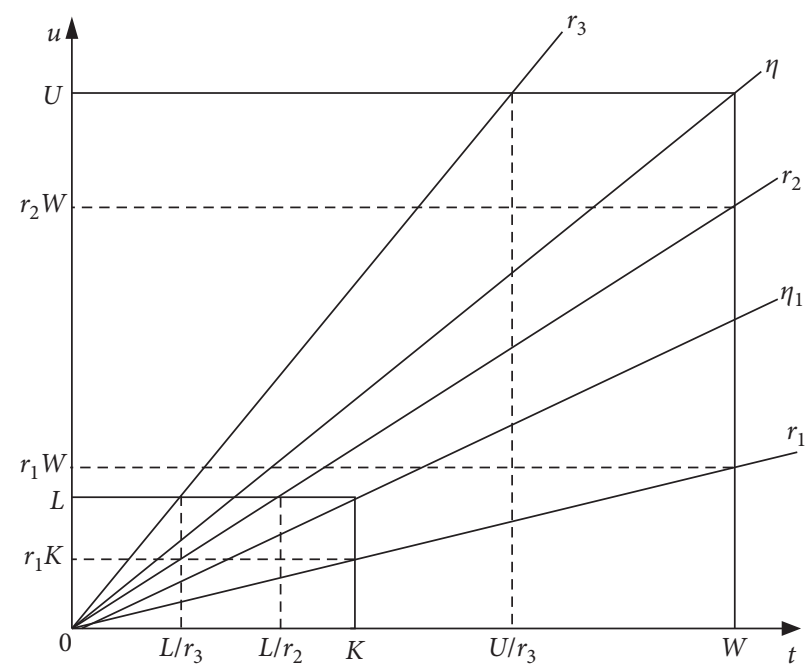

Figure 1: Three subcases for the case of $\eta_{1}<\eta$.

$$
\begin{aligned}
E[M(t)] & =\int_{0}^{Y} \lambda_{0}(t \mid r) \mathrm{d} t+\int_{Y}^{2 Y} \lambda_{1}(t \mid r) \mathrm{d} t+\cdots+\int_{(l-1) Y}^{l Y} \lambda_{(n-1)}(t \mid r) \mathrm{d} t+\int_{l Y}^{t} \lambda_{n}(t \mid r) \mathrm{d} t \\
& =\sum_{j=1}^{l} \int_{(j-1) Y}^{j Y} \lambda_{(j-1)}(t \mid r) \mathrm{d} t+\int_{l Y}^{t} \lambda_{l}(t \mid r) \mathrm{d} t,
\end{aligned}
$$

where $\lambda_{h}(t \mid r)=\lambda(t \mid r)-h \lambda_{p}(h=0,1, \ldots, l)$.

From equations (8) and (9), for Case 1, the mean warranty servicing cost over $(0, t)$ is

$$
A_{0}(t)=l C_{p}+C_{m} E[M(t)]
$$

where $C_{p}$ and $C_{m}$ are costs for per PM action and per minor repair action.

(2) Case 2. In this case, suppose that $M_{T}$ is the number of shocks over $(0, t)$. According to modeling assumptions, $M_{T}$ takes values $1,2, \ldots, N-1$ and the probability is

$P\left(M_{T}=i\right)=P(N(t)=i) p^{i}, i=1,2, \ldots, N-1$.

Let $B_{i}(t)$ denote the mean total warranty cost over $(0, t)$, given $M_{T}=i(i=1,2, \ldots, N-1)$. Given $M_{T}=1$ and $T_{1}=t_{1}, B_{1}(t)$ is the sum of warranty servicing cost over $\left(0, t_{1}\right)$ (denoted by $B_{11}\left(t_{1}\right)$ ) and that over $\left(t_{1}, t\right)$ (denoted by $\left.B_{12}\left(t-t_{1}\right)\right)$. Suppose that $n_{t_{1}}$ is the number of PM activities over $\left(0, t_{1}\right)$; then, $n_{t_{1}}=\max \left\{j \mid j Y \leq t_{1}, j \geq 0\right\}$. From the modeling assumptions, it follows that

$$
\begin{aligned}
B_{11}\left(t_{1}\right)= & n_{t_{1}} C_{p} \\
& +C_{m}\left[\sum_{j=0}^{n_{t_{1}}} \int_{(j-1) y}^{j y} \lambda_{j-1}(t \mid r) \mathrm{d} t+\int_{n_{t_{1}} y}^{t_{1}} \lambda_{n_{t_{1}}}(t \mid r) \mathrm{d} t\right],
\end{aligned}
$$

where the first term is the cost for the PM activities over $\left(0, t_{1}\right)$ and the second one is for minor repairs. The conditional intensity function over $\left(t_{1}, t\right)$ increases by $\lambda_{s}$ because the first shock occurs at time $t_{1}$. Furthermore, no shock arrivals are over $\left(t_{1}, t\right)$. Therefore,

$$
\begin{aligned}
B_{12}\left(t-t_{1}\right)= & C_{m} \int_{t_{1}}^{\left(n_{t_{1}}+1\right) y}\left(\lambda_{n_{1}}(t \mid r)+\lambda_{s}\right) \mathrm{d} t+C_{m} \sum_{n_{1}+1}^{n-1} \int_{j y}^{(j+1) y}\left(\lambda_{j}(t \mid r)+\lambda_{s}\right) \mathrm{d} t \\
& +C_{m} \int_{l y}^{t} \lambda_{l}(t \mid r)+\lambda_{s} \mathrm{~d} t+\left(l-n_{t_{1}}\right) C_{p} .
\end{aligned}
$$

Combining the terms on $\lambda_{s}$ in equation (13), we have 


$$
\begin{aligned}
B_{12}\left(t-t_{1}\right)= & C_{m}\left[\int_{t_{1}}^{\left(n_{t_{1}}+1\right) y} \lambda_{n_{1}}(t \mid r) \mathrm{d} t+\sum_{n_{1}+1}^{n-1} \int_{j y}^{(j+1) y} \lambda_{j}(t \mid r) \mathrm{d} t+\int_{l y}^{t} \lambda_{n}(t \mid r) \mathrm{d} t\right] \\
& +C_{m} \lambda_{s}\left(t-t_{1}\right)+\left(l-n_{t_{1}}\right) C_{p}
\end{aligned}
$$

where the first term is the cost of minor repair activities in the case that no shocks arrival are over $\left(t_{1}, t\right)$ and the second one is that of minor repair activities due to the increase in the intensity function.
From the law of total probability and using equation (10) into equations (13) and (14), we can conclude that

$$
\begin{aligned}
B_{1}(t) & =\int_{0}^{t}\left[B_{11}\left(t_{1}\right)+B_{12}\left(t-t_{1}\right)\right] f_{(1)}\left(t_{1}\right) \mathrm{d} t_{1} \\
& =\int_{0}^{t}\left[\left(l C_{p}+C_{m}\left(\sum_{j=0}^{l-1} \int_{(j-1) y}^{j y} \lambda_{j}(t \mid r) \mathrm{d} t\right)+\int_{l y}^{t} \lambda_{l}(t \mid r) d t\right)+C_{m} \lambda_{s}\left(t-t_{1}\right)\right] f_{(1)}\left(t_{1}\right) \mathrm{d} t_{1} \\
& =\int_{0}^{t}\left[A_{0}(t)+C_{m} \lambda_{s}\left(t-t_{1}\right)\right] f_{(1)}\left(t_{1}\right) \mathrm{d} t_{1} .
\end{aligned}
$$

Equation (15) states that, given $T_{1}=t_{1}, B_{1}(t)$ is the sum of the warranty servicing cost over $(0, t)$ in the case that no shock arrivals over $(0, t)$ and that of minor repair activities due to the increase in the intensity function $C_{m} \lambda_{s}\left(t-t_{1}\right)$.

Similarly, for $j=2, \cdots, N-1$,

$$
B_{j}(t)=\int_{0}^{t} \ldots \int_{t_{j-1}}^{t}\left[A_{0}(t)+\sum_{i=2}^{j-1}(i-1) C_{m} \lambda_{s}\left(t_{i}-t_{i-1}\right)+j C_{m} \lambda_{s}\left(t-t_{j}\right)\right] f_{(1) \ldots(j)}\left(t_{1}, \ldots, t_{j}\right) \mathrm{d} t_{j} \cdots \mathrm{d} t_{1} .
$$

(3) Case 3. In that case, let $N_{T}$ be the number of shocks over $(0, t)$ at the time of the first replacement. $N_{T}$ takes values $1,2,3, \cdots, N$ and the probability is

$$
\begin{aligned}
P\left(N_{T}=i\right) & =\sum_{j=i}^{\infty} P\{N(t)=j\} p^{i-1}(1-p) i=1,2,3, \ldots, N-1, \\
P\left(N_{T}=N\right) & =\sum_{j=N}^{\infty} P\{N(t)=j\} p^{N-1} .
\end{aligned}
$$

The event $N_{T}=1$ occurs when the product is replaced on the first shock over $(0, t)$. Given $T_{1}=t_{1}$, the warranty servicing cost over $(0, t)$ and $C_{1}(t)$, consists of the following three parts: the warranty servicing cost $(0, t)$ for the case that no shocks arrivals over $A_{0}\left(t_{1}\right)$, the cost of a replacement $C_{r}$, and the warranty servicing cost over $\left(t_{1}, t\right), H\left(t-t_{1}\right)$. Therefore,

$$
C_{1}(t)=\int_{0}^{t}\left[A_{0}\left(t_{1}\right)+C_{r}+H\left(t-t_{1}\right)\right] f_{(1)}\left(t_{1}\right) \mathrm{d} t_{1} .
$$

Similarly, given $N_{T}=k(k=2, \ldots, N)$, the warranty servicing cost over $(0, t)$ is

$$
C_{k}(t)=\int_{0}^{t} \cdots \int_{t_{k-1}}^{t}\left[A_{0}\left(t_{k}\right)+\sum_{i=1}^{k-1} i C_{m} \lambda_{s}\left(t_{i+1}-t_{i}\right)+C_{r}+H\left(t-t_{k}\right)\right] f_{(1) \ldots(k)}\left(t_{1}, \ldots, t_{k}\right) \mathrm{d} t_{k} \cdots \mathrm{d} t_{1}
$$

Changing the order of integration and substituting equation (6) into the preceding yield that 


$$
\begin{aligned}
C_{k}(t) & =\int_{0}^{t} \int_{0}^{t_{k}} \cdots \int_{0}^{t_{2}}\left[A_{0}\left(t_{k}\right)+\sum_{i=1}^{k-1} i C_{m} \lambda_{s}\left(t_{i+1}-t_{i}\right)+C_{r}+H\left(t-t_{k}\right)\right] f_{(1) \ldots(k)}\left(t_{1}, \ldots, t_{k}\right) \mathrm{d} t_{1} \cdots \mathrm{d} t_{k-1} \mathrm{~d} t_{k} \\
& =\int_{0}^{t}\left[A_{0}\left(t_{k}\right)+H\left(t-t_{k}\right)\right] f_{(k)}\left(t_{k}\right) \mathrm{d} t_{k}+C_{r}+C_{m} \lambda_{s} \frac{k^{2}-k}{2(n+1)} t .
\end{aligned}
$$

By taking the expectation for the conditional expectation of $H(t)$, we have

$$
\begin{aligned}
H(t)= & P\{N(t)=0\} A_{0}(t)+\sum_{j=1}^{N-1} P\{N(t)=j\} p^{j} B_{j}(t) \\
& +\sum_{k=1}^{N-1} \sum_{j=k}^{\infty} P\{N(t)=j\} p^{k-1}(1-p) C_{k}(t) \\
& +\sum_{j=N}^{\infty} P\{N(t)=j\} p^{N-1} C_{N}(t),
\end{aligned}
$$

or equivalently,

$$
\begin{aligned}
H(t)= & \sum_{k=1}^{N-1} \sum_{j=k}^{\infty} P\{N(t)=j\} p^{k-1}(1-p) \int_{0}^{t} H\left(t-t_{k}\right) \mathrm{d} F_{(k)}\left(t_{k}\right) \\
& +\sum_{j=N}^{\infty} P\{N(t)=j\} p^{N-1} \int_{0}^{t} H\left(t-t_{N}\right) \mathrm{d} F_{(N)}\left(t_{N}\right)+J(t),
\end{aligned}
$$

where $F_{(k)}(t)=\int_{0}^{t} f_{(k)}(u) \mathrm{d} u(k=1,2, \ldots)$ and

$$
\begin{aligned}
J(t)= & P\{N(t)=0\} A_{0}(t)+\sum_{j=1}^{N-1} P\{N(t)=j\} p^{j} B_{j}(t) \\
& +\sum_{k=1}^{N-1} \sum_{j=k}^{\infty} P\{N(t)=j\} p^{k-1}(1-p)\left(\int_{0}^{t} A_{0}\left(t_{k}\right) f_{(k)}\left(t_{k}\right) \mathrm{d} t_{k}+C_{r}+C_{m} \lambda_{s} \frac{k^{2}-k}{2(n+1)} t\right) \\
& +\sum_{j=N}^{\infty} P\{N(t)=j\} p^{N-1}\left(\int_{0}^{t} A_{0}\left(t_{N}\right) f_{(N)}\left(t_{N}\right) \mathrm{d} t_{N}+C_{r}+C_{m} \lambda_{s} \frac{N^{2}-N}{2(n+1)} t\right) .
\end{aligned}
$$

Note $J(t)$ is a function of $t$. By the method of integration by parts, equation (22) reduces to

$$
\begin{aligned}
H(t)= & \sum_{k=1}^{N-1} \int_{0}^{t} F_{(k)}\left(t-t_{k}\right) \mathrm{d}\left(\sum_{j=k}^{\infty} P\{N(t)=j\} p^{k-1}(1-p) H\left(t_{k}\right)\right) \\
& +\int_{0}^{t} F_{(N)}\left(t-t_{N}\right) \mathrm{d}\left(\sum_{j=N}^{\infty} P\{N(t)=j\} p^{N-1} H\left(t_{N}\right)\right)+J(t) .
\end{aligned}
$$

For the case of $\eta_{1}<\eta$, removing the conditioning on $R$, the total mean warranty servicing cost over the two-dimensional rectangle warranty region $[0, W) \times t[0, U)$ can be given by

$$
\begin{aligned}
C(N, K, L)= & \int_{0}^{\eta_{1}} H(W) g(r) \mathrm{d} r+\int_{\eta_{1}}^{\eta} H(W) g(r) \mathrm{d} r \\
& +\int_{\eta}^{\infty} H \frac{U}{r} g(r) \mathrm{d} r .
\end{aligned}
$$

Similarly, for the case of $\eta_{1} \geq \eta$,

$$
\begin{aligned}
C(N, K, L)= & \int_{0}^{\eta} H(W) g(r) \mathrm{d} r+\int_{\eta}^{\eta_{1}} H \frac{U}{r} g(r) \mathrm{d} r \\
& +\int_{\eta_{1}}^{\infty} H \frac{U}{r} g(r) \mathrm{d} r .
\end{aligned}
$$

3.3. Numerical Integration Approximation Algorithm of the Warranty Servicing Cost. Although the renewal equation about the warranty servicing cost is obtained in Section 3.2, the analytic solution cannot be given. Based on direct numerical Riemann-Stieltjes integration, an approximation algorithm of the cost will be given in this section (see [37]). 
By the idea of the usual midpoint method in numerical analysis,

$$
\int_{a}^{b} f(x) d g(x) \approx \sum_{i=1}^{n} f\left(x_{(i-1 / 2)}\right)\left(g\left(x_{i}\right)-g\left(x_{i-1}\right)\right),
$$

where $x_{(i-1 / 2)}=\left(x_{i}+x_{i-1}\right) / 2$.
Based on equation (27), $H(t)$ can be approximated by the following recursive algorithm.

For given $t$ and $r$, dividing the interval $(0, t)$ into $n_{1}$ equal subintervals, the endpoints $v_{i}\left(0 \leq i \leq n_{1}\right)$ satisfy the condition $0=v_{0}<v_{1}<\cdots<v_{i}<\cdots v_{n_{1}}=t$. By equation (24), we have

$$
\begin{aligned}
H\left(v_{i}\right)= & \sum_{k=1}^{N-1} \sum_{j=k}^{\infty} P\left\{N\left(v_{i}\right)=j\right\} p^{k-1}(1-p) \int_{0}^{v_{i}} F_{(k)}\left(v_{i}-t_{k}\right) \mathrm{d} H\left(t_{k}\right) \\
& +\sum_{j=N}^{\infty} P\left\{N\left(v_{i}\right)=j\right\} p^{N-1} \int_{0}^{v_{i}} F_{(N)}\left(v_{i}-t_{N}\right) \mathrm{d} H\left(t_{N}\right)+J\left(v_{i}\right) .
\end{aligned}
$$

Using equation (27),

$$
\begin{aligned}
H\left(v_{i}\right) \approx & \sum_{m=1}^{i-1} \sum_{k=1}^{N-1} \sum_{j=k}^{\infty} P\left\{N\left(v_{i}\right)=j\right\} p^{k-1}(1-p) F_{(k)}\left(v_{i}-\frac{v_{m}+v_{m-1}}{2}\right)\left(H\left(v_{m}\right)-H\left(v_{m-1}\right)\right) \\
& +\sum_{m=1}^{i-1} \sum_{j=N}^{\infty} P\left\{N\left(v_{i}\right)=j\right\} p^{N-1} F_{(N)}\left(v_{i}-\frac{v_{m}+v_{m-1}}{2}\right)\left(H\left(v_{m}\right)-H\left(v_{m-1}\right)\right)+J\left(v_{i}\right) .
\end{aligned}
$$

From equation (29), $H\left(v_{i}\right)$ can be obtained recursively where through

$$
H\left(v_{i}\right)=\frac{J\left(v_{i}\right)+S_{i}-F\left(v_{i}-v_{i}+v_{i-1} / 2\right) H\left(v_{i-1}\right)}{1-F\left(v_{i}-v_{i}+v_{i-1} / 2\right)},
$$

$$
\begin{aligned}
J\left(v_{i}\right)= & P\left\{N\left(v_{i}\right)=0\right\} A_{0}\left(v_{i}\right)+\sum_{j=1}^{N-1} P\left\{N\left(v_{i}\right)=j\right\} p^{j} B_{j}\left(v_{i}\right) \\
& +\sum_{k=1}^{N-1} \sum_{j=k}^{\infty} P\left\{N\left(v_{i}\right)=j\right\} p^{k-1}(1-p)\left(\int_{0}^{v_{i}} A_{0}\left(t_{k}\right) f_{(k)}\left(t_{k}\right) \mathrm{d} t_{k}+C_{r}+C_{m} \lambda_{s} \frac{k^{2}-k}{2(n+1)} v_{i}\right) \\
& +\sum_{j=N}^{\infty} P\left\{N\left(v_{i}\right)=j\right\} p^{N-1}\left(\int_{0}^{v_{i}} A_{0}\left(t_{N}\right) f_{(N)}\left(t_{N}\right) \mathrm{d} t_{N}+C_{r}+C_{m} \lambda_{s} \frac{N^{2}-N}{2(n+1)} v_{i}\right), \\
S_{i}= & \sum_{m=1}^{i-1} \sum_{k=1}^{N-1} \sum_{j=k}^{\infty} P\left\{N\left(v_{i}\right)=j\right\} p^{k-1}(1-p) F_{k}\left(v_{i}-\frac{v_{m}+v_{m-1}}{2}\right)\left(H\left(v_{m}\right)-H\left(v_{m-1}\right)\right) \\
& +\sum_{m=1}^{i-1} \sum_{j=N}^{\infty} P\left\{N\left(v_{i}\right)=j\right\} p^{N-1} F_{N}\left(v_{i}-\frac{v_{m}+v_{m-1}}{2}\right)\left(H\left(v_{m}\right)-H\left(v_{m-1}\right)\right),
\end{aligned}
$$


TABLE 1: The parameters of the model.

\begin{tabular}{lccccc}
\hline$\lambda_{p}$ & $\lambda_{s}$ & $p$ & $C_{m}$ & $C_{p}$ & \\
\hline 0.5 & 0.02 & 0.85 & $\$ 8$ & $\$ 10$ & $C_{r}$ \\
\hline
\end{tabular}

$$
\begin{aligned}
F\left(v_{i}-\frac{v_{i}+v_{i-1}}{2}\right)= & \sum_{k=1}^{N-1} \sum_{j=k}^{\infty} P\left\{N\left(v_{i}\right)=j\right\} p^{k-1}(1-p) F_{k}\left(v_{i}-\frac{v_{i}+v_{i-1}}{2}\right) \\
& +\sum_{j=N}^{\infty} P\left\{N\left(v_{i}\right)=j\right\} p^{N-1} F_{N}\left(v_{i}-\frac{v_{m}+v_{m-1}}{2}\right) .
\end{aligned}
$$

The total mean warranty servicing cost $C(N, K, L)$ can be approximated by equations (25) and (26), depending on the relationships between the ratios $\eta_{1}=(K / L)$ and $\eta=(W / U)$.

\section{A Numerical Example}

In this section, a numerical example is presented to illustrate the applicability of the proposed model above.

Suppose a repairable product is sold with a free repair rectangle warranty period. The age and usage limits of the two-dimensional warranty are $W=3$ years and $U=3 \times 10^{4}$ $\mathrm{km}$, respectively. Given the usage rate $R=r$, the original conditional failure intensity function $E\left[C^{*}(\Omega)\right]$, where $\theta_{0}=0.1, \theta_{1}=0.2, \theta_{2}=0.7$, and $\theta_{3}=0.7$. Suppose that the usage rate $R$ is uniformly distributed in the interval $(0.1,2.9)$. The other parameters of the model are listed in Table 1 (see [12]).

4.1. Optimization of the Decision Variables. Assuming such parameter values aforementioned, given $N=3$, we can obtain the mean servicing cost over the whole warranty coverage for various 2D PM interval $(K, L)$ and their corresponding cost, $C(3, K, L)$, by using Matlab software. See Table 2, for detail. The results are illustrated in Figure 2. The table and figure indicate that the mean cost is minimized when $(K, L)=(1.8,1.6)$ and mean cost is $\$ 78.5762$.

In a similar method, we can obtain the optimal 2D PM interval $\left(K^{*}, L^{*}\right)$ for various $N$. The results are listed in Table 3 and illustrated in Figure 3. The table and figure indicate that the mean cost is minimized when $\left(N^{*}, K^{*}, L^{*}\right)=(6,1.6,1.6)$. The corresponding mean cost is $\$ 68.6760$, which is smaller than that of $N=3$.

\subsection{The Effects of Model Parameters on the Optimal 2D PM} Interval. To gain more insights into the model, the effects of product parameters, such as $C_{m}, C_{p}, C_{r}, \lambda, \lambda_{s}$, and $\lambda_{p}$, on the optimal 2D PM interval and the mean cost rates over the warranty region are given in this section.

Setting $N=3$, let average cost per minor repair, $C_{m}$, change from 4 to 12 by Step 2 and the other product parameters be the same to those in Section 4.1. The optimal strategies $\left(K^{*}, L^{*}\right)$ and its corresponding mean cost $C\left(3, K^{*}, L^{*}\right)$ are presented in Table 4 and illustrated in Figure 4 . The table and figure indicate that the mean cost increases and the optimal age and usage PM intervals decrease with the increase of $C_{m}$. It is consistent with intuition that the mean cost increases with the increase of the average cost per minor repair. With the decrease of the length of 2D PM interval, the frequency of PM activities increases and the number of minor repairs decreases according. Hence, the mean cost can be minimized by decreasing PM intervals as $C_{m}$ increases.

Similarly, the optimal strategies $\left(K^{*}, L^{*}\right)$ and its corresponding mean cost $C\left(3, K^{*}, L^{*}\right)$ for various average cost per $\mathrm{PM} C_{p}$ are presented in Table 5 and illustrated in Figure 5. The table and figure indicate the optimal age PM interval increase slowly with the increase of $C_{p}$. It is natural that the mean cost can be optimized by decreasing the frequency of PM, that is, by increasing the length of PM interval, as $C_{p}$ increases.

The optimal strategies $\left(K^{*}, L^{*}\right)$ and the corresponding mean cost $C\left(3, K^{*}, L^{*}\right)$ for various cost of per replacement, $C_{r}$, are listed in Table 6 and illustrated in Figure 6 . The table and figure indicate that $C_{r}$ has little effects on the optimal 2D PM interval. According to the model assumption, a replacement occurs with probability $p$ when a shock arrives. Hence, for the fixed number of shocks before replacement $N=3$, the mean servicing cost increases with the increase of $\mathrm{C}_{r}$; on the contrary, the optimal 2D PM interval remains static.

The optimal strategies $\left(K^{*}, L^{*}\right)$ and the corresponding mean cost $C\left(3, K^{*}, L^{*}\right)$ for $\lambda, \lambda_{s}$, and $\lambda_{p}$ are listed and illustrated in Table 7-9 and Figures 7-9, respectively.

Table 7 and Figure 7 indicate that the optimal age PM interval increases with the increase of arrival rate of shocks $\lambda$. An intuitive explanation of this trend is as follows. The higher $\lambda$ is, the higher the frequency of replacements is. By reducing the frequency of PM activities, that is, extending the PM interval, the mean servicing cost may be reduced.

With the increase of $\lambda_{s}$, the number of minor repairs increases; therefore, the mean servicing cost increases, as shown in Table 8 and Figure 8 . The constant 2D PM interval in Table 8 may be caused by the parameter setting.

Table 9 and Figure 9 indicate that the mean servicing cost decreases with the increase of $\lambda_{p}$. The trend is due to the decrease of minor repairs caused by the increase of $\lambda_{p}$. To some extent, the decrease trend of the optimal age PM interval (in other words, the increase in the frequency of PM 
TABle 2: The mean cost for various $(K, L)(N=3)$.

\begin{tabular}{|c|c|c|c|c|c|c|c|c|}
\hline$K$ & $L$ & $C(3, K, L)$ & $K$ & $L$ & $C(3, K, L)$ & $K$ & $L$ & $C(3, K, L)$ \\
\hline \multirow{15}{*}{0.2} & 0.2 & 147.7801 & \multirow{15}{*}{0.4} & 0.2 & 140.9630 & \multirow{15}{*}{0.6} & 0.2 & 140.4417 \\
\hline & 0.4 & 122.9759 & & 0.4 & 109.4775 & & 0.4 & 108.2251 \\
\hline & 0.6 & 119.9012 & & 0.6 & 98.5383 & & 0.6 & 95.9022 \\
\hline & 0.8 & 119.9012 & & 0.8 & 96.1114 & & 0.8 & 92.6010 \\
\hline & 1.0 & 119.9012 & & 1.0 & 96.0579 & & 1.0 & 92.2928 \\
\hline & 1.2 & 119.9012 & & 1.2 & 94.9622 & & 1.2 & 89.8861 \\
\hline & 1.4 & 119.9012 & & 1.4 & 94.9622 & & 1.4 & 89.9341 \\
\hline & 1.6 & 119.9012 & & 1.6 & 94.9622 & & 1.6 & 88.5788 \\
\hline & 1.8 & 119.9012 & & 1.8 & 94.9622 & & 1.8 & 88.5892 \\
\hline & 2.0 & 119.9012 & & 2.0 & 94.9622 & & 2.0 & 88.5892 \\
\hline & 2.2 & 119.9012 & & 2.2 & 94.9622 & & 2.2 & 88.5892 \\
\hline & 2.4 & 119.9012 & & 2.4 & 94.9622 & & 2.4 & 88.5892 \\
\hline & 2.6 & 119.9012 & & 2.6 & 94.9622 & & 2.6 & 88.5892 \\
\hline & 2.8 & 119.9012 & & 2.8 & 94.9622 & & 2.8 & 88.5892 \\
\hline & 3.0 & 119.9012 & & 3.0 & 94.9622 & & 3.0 & 88.5892 \\
\hline \multirow{15}{*}{0.8} & 0.2 & 139.5827 & \multirow{15}{*}{1.0} & 0.2 & 139.6552 & \multirow{15}{*}{1.2} & 0.2 & 139.5289 \\
\hline & 0.4 & 106.3715 & & 0.4 & 106.5164 & & 0.4 & 106.1375 \\
\hline & 0.6 & 92.7894 & & 0.6 & 93.0359 & & 0.6 & 92.2441 \\
\hline & 0.8 & 88.9886 & & 0.8 & 89.3238 & & 0.8 & 88.4248 \\
\hline & 1.0 & 88.8392 & & 1.0 & 89.0301 & & 1.0 & 87.8702 \\
\hline & 1.2 & 85.7088 & & 1.2 & 85.8045 & & 1.2 & 84.5662 \\
\hline & 1.4 & 85.7655 & & 1.4 & 85.8727 & & 1.4 & 84.6695 \\
\hline & 1.6 & 82.9178 & & 1.6 & 82.1352 & & 1.6 & 80.5538 \\
\hline & 1.8 & 82.9627 & & 1.8 & 82.1893 & & 1.8 & 80.6122 \\
\hline & 2.0 & 83.0109 & & 2.0 & 82.2878 & & 2.0 & 80.7487 \\
\hline & 2.2 & 83.0232 & & 2.2 & 82.3203 & & 2.2 & 80.7876 \\
\hline & 2.4 & 83.0299 & & 2.4 & 82.3417 & & 2.4 & 80.8281 \\
\hline & 2.6 & 83.0299 & & 2.6 & 82.3803 & & 2.6 & 80.9063 \\
\hline & 2.8 & 83.0299 & & 2.8 & 82.3979 & & 2.8 & 80.9163 \\
\hline & 3.0 & 83.0299 & & 3.0 & 82.4838 & & 3.0 & 81.8319 \\
\hline \multirow{15}{*}{1.4} & 0.2 & 139.5237 & \multirow{15}{*}{1.6} & 0.2 & 139.3684 & \multirow{15}{*}{1.8} & 0.2 & 139.3630 \\
\hline & 0.4 & 106.1164 & & 0.4 & 105.8058 & & 0.4 & 105.7950 \\
\hline & 0.6 & 92.1810 & & 0.6 & 91.5508 & & 0.6 & 91.5345 \\
\hline & 0.8 & 88.3882 & & 0.8 & 87.6117 & & 0.8 & 87.5900 \\
\hline & 1.0 & 87.8034 & & 1.0 & 86.8782 & & 1.0 & 86.8571 \\
\hline & 1.2 & 84.5140 & & 1.2 & 83.4499 & & 1.2 & 83.4277 \\
\hline & 1.4 & 84.6259 & & 1.4 & 83.2242 & & 1.4 & 83.1997 \\
\hline & 1.6 & 80.1514 & & 1.6 & 78.6036 & & 1.6 & 78.5762 \\
\hline & 1.8 & 80.2097 & & 1.8 & 78.6671 & & 1.8 & 78.5954 \\
\hline & 2.0 & 80.3775 & & 2.0 & 78.8598 & & 2.0 & 78.8083 \\
\hline & 2.2 & 80.4272 & & 2.2 & 78.9109 & & 2.2 & 78.8501 \\
\hline & 2.4 & 80.4743 & & 2.4 & 78.9555 & & 2.4 & 78.9040 \\
\hline & 2.6 & 80.5848 & & 2.6 & 79.0916 & & 2.6 & 79.0624 \\
\hline & 2.8 & 80.6034 & & 2.8 & 79.1092 & & 2.8 & 79.0837 \\
\hline & 3.0 & 81.7422 & & 3.0 & 80.5098 & & 3.0 & 80.0259 \\
\hline \multirow{15}{*}{2.0} & 0.2 & 139.3792 & \multirow{15}{*}{2.2} & 0.2 & 139.3792 & \multirow{15}{*}{2.4} & 0.2 & 139.3792 \\
\hline & 0.4 & 105.8274 & & 0.4 & 105.8241 & & 0.4 & 105.8388 \\
\hline & 0.6 & 91.5831 & & 0.6 & 91.5765 & & 0.6 & 91.6059 \\
\hline & 0.8 & 87.6548 & & 0.8 & 87.6449 & & 0.8 & 87.6890 \\
\hline & 1.0 & 86.9382 & & 1.0 & 86.9249 & & 1.0 & 86.9837 \\
\hline & 1.2 & 83.5250 & & 1.2 & 83.5084 & & 1.2 & 83.5819 \\
\hline & 1.4 & 83.3132 & & 1.4 & 83.2933 & & 1.4 & 83.3767 \\
\hline & 1.6 & 78.7059 & & 1.6 & 78.6827 & & 1.6 & 78.7773 \\
\hline & 1.8 & 78.7414 & & 1.8 & 78.7148 & & 1.8 & 78.8215 \\
\hline & 2.0 & 78.9720 & & 2.0 & 78.9421 & & 2.0 & 79.0615 \\
\hline & 2.2 & 79.0147 & & 2.2 & 78.9816 & & 2.2 & 79.1140 \\
\hline & 2.4 & 79.0632 & & 2.4 & 79.0314 & & 2.4 & 79.1786 \\
\hline & 2.6 & 79.2395 & & 2.6 & 79.2224 & & 2.6 & 79.3817 \\
\hline & 2.8 & 79.2695 & & 2.8 & 79.2580 & & 2.8 & 79.4205 \\
\hline & 3.0 & 80.7800 & & 3.0 & 80.7843 & & 3.0 & 80.7595 \\
\hline
\end{tabular}


TABLE 2: Continued.

\begin{tabular}{|c|c|c|c|c|c|c|c|c|}
\hline$K$ & $L$ & $C(3, K, L)$ & $K$ & $L$ & $C(3, K, L)$ & $K$ & $L$ & $C(3, K, L)$ \\
\hline \multirow{14}{*}{2.6} & 0.2 & 139.3792 & \multirow{14}{*}{2.8} & 0.2 & 139.3792 & \multirow{14}{*}{3.0} & 0.2 & 139.3792 \\
\hline & 0.4 & 105.8386 & & 0.4 & 105.8419 & & 0.4 & 105.8548 \\
\hline & 0.6 & 91.6055 & & 0.6 & 91.6122 & & 0.6 & 91.6379 \\
\hline & 0.8 & 87.6884 & & 0.8 & 87.6997 & & 0.8 & 87.7253 \\
\hline & 1.0 & 86.9762 & & 1.0 & 86.9862 & & 1.0 & 87.0247 \\
\hline & 1.2 & 83.5812 & & 1.2 & 83.5946 & & 1.2 & 83.6459 \\
\hline & 1.4 & 83.3757 & & 1.4 & 83.3925 & & 1.4 & 83.4438 \\
\hline & 1.6 & 78.7761 & & 1.6 & 78.7974 & & 1.6 & 78.8615 \\
\hline & 1.82 .0 & 78.741479 .0531 & & 1.82 .0 & 78.714879 .0766 & & 1.82 .0 & 78.821579 .1572 \\
\hline & 2.2 & 79.1016 & & 2.2 & 79.1252 & & 2.2 & 79.2150 \\
\hline & 2.4 & 79.1630 & & 2.4 & 79.1943 & & 2.4 & 79.2969 \\
\hline & 2.6 & 79.3797 & & 2.6 & 79.4099 & & 2.6 & 79.5182 \\
\hline & 2.8 & 79.4191 & & 2.8 & 79.4526 & & 2.8 & 79.5679 \\
\hline & 3.0 & 81.5805 & & 3.0 & 82.4474 & & 3.0 & 82.5756 \\
\hline
\end{tabular}

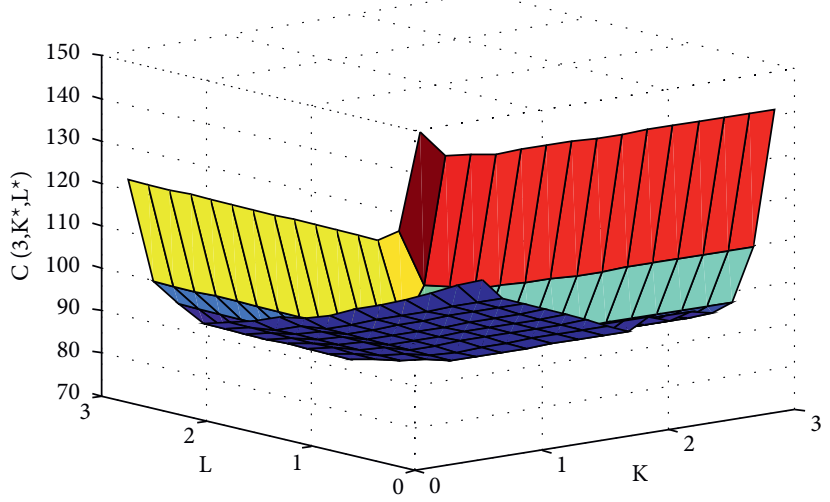

Figure 2: The mean cost for various $(K, L)(N=3)$.

TABle 3: The minimal mean cost for various $N$.

\begin{tabular}{lllr}
\hline$N$ & $K^{*}$ & $L^{*}$ & $C\left(N, K^{*}, L^{*}\right)$ \\
\hline 1 & 2.8 & 2.8 & 140.4017 \\
2 & 1.8 & 1.8 & 120.7821 \\
3 & 1.8 & 1.6 & 78.5762 \\
4 & 1.6 & 1.6 & 71.5773 \\
5 & 1.6 & 1.6 & 69.4185 \\
6 & 1.6 & 1.6 & $\mathbf{6 8 . 6 7 6 0}$ \\
7 & 1.6 & 1.6 & 68.7176 \\
8 & 1.6 & 1.6 & 68.7256 \\
\hline
\end{tabular}

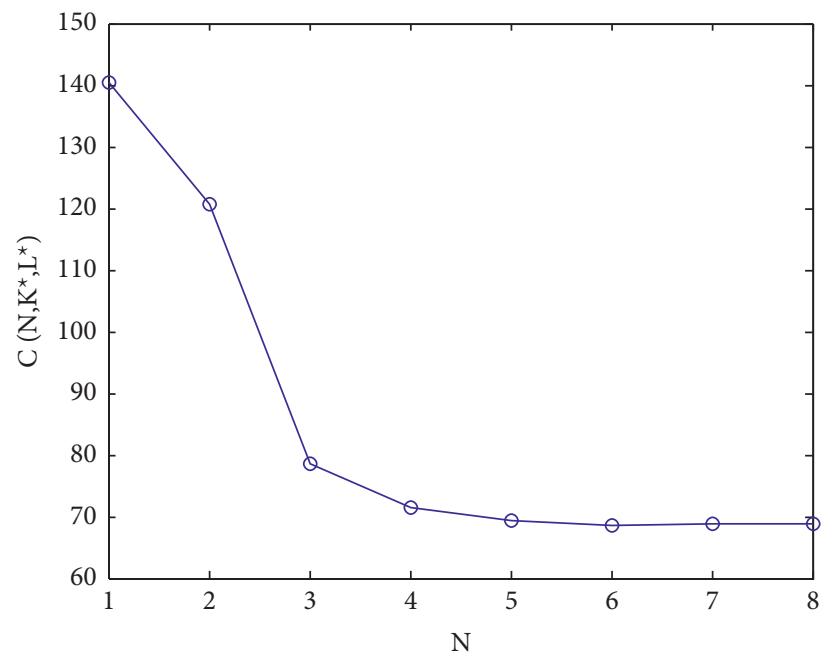

Figure 3: The minimal mean cost for various $N$. 
TABLe 4: The minimal mean cost for various $C_{m}$.

\begin{tabular}{lccccc}
\hline$C_{m}$ & 4 & 6 & 8 & 10 & 12 \\
\hline$K^{*}$ & 1.8 & 1.8 & 1.8 & 1.8 & 1.6 \\
$L^{*}$ & 1.8 & 73.1610 & 1.6 & 1.6 & 1.6 \\
$C\left(3, K^{*}, L^{*}\right)$ & 67.7266 & 78.5762 & 83.9356 & 89.2677 \\
\hline
\end{tabular}

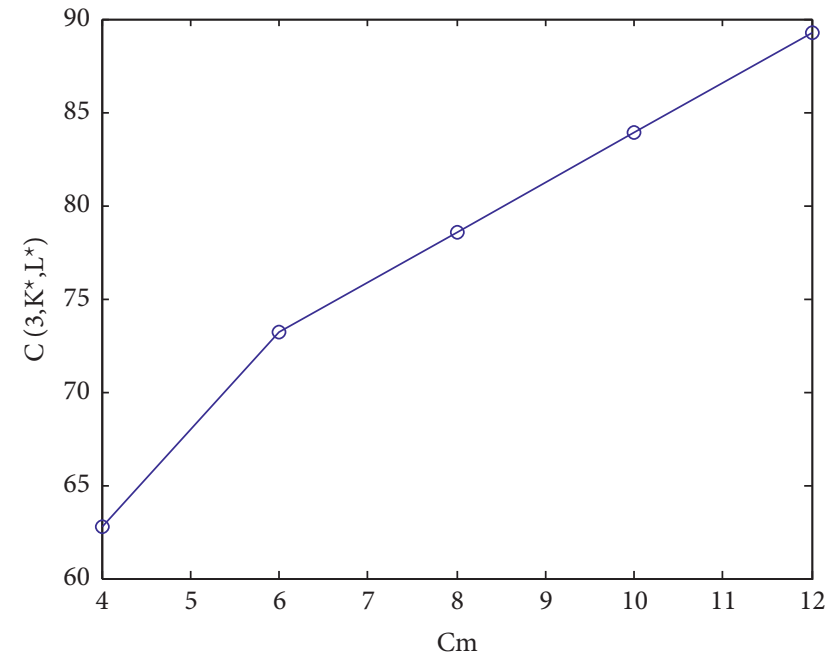

Figure 4: The minimal mean cost for various $C_{m}$.

TABLE 5: The minimal mean cost for various $C_{p}$.

\begin{tabular}{lccccc}
\hline$C_{p}$ & 5 & 10 & 15 & 20 & 25 \\
\hline$K^{*}$ & 1.6 & 1.8 & 1.8 & 1.8 & 1.8 \\
$L^{*}$ & 1.6 & 1.6 & 1.6 & 1.6 & 1.6 \\
$C\left(3, K^{*}, L^{*}\right)$ & 74.7829 & 78.5762 & 82.3027 & 86.0292 & 89.7557 \\
\hline
\end{tabular}

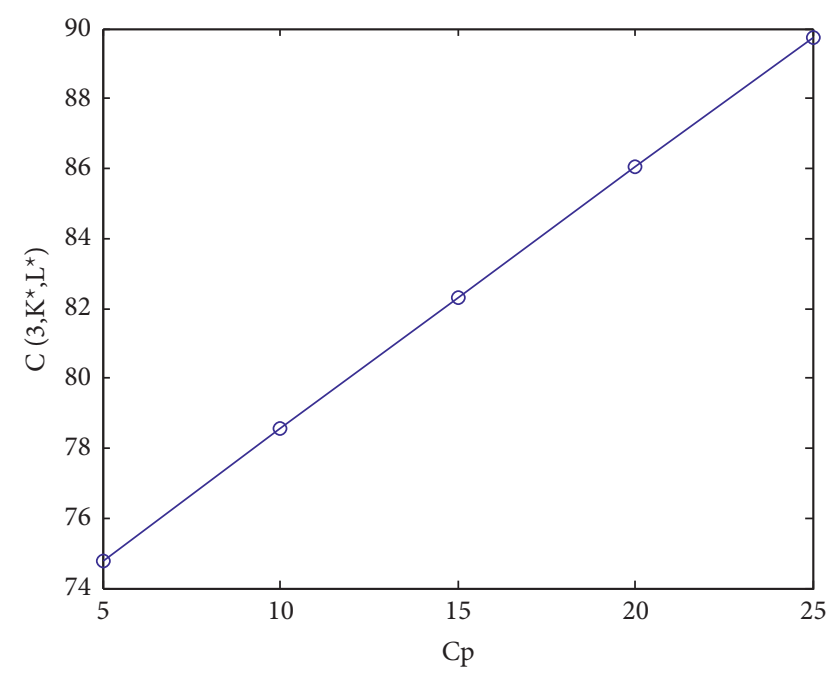

Figure 5: The minimal mean cost for various $C_{p}$.

activities) with the increase of $\lambda_{p}$ in Table 9 is affected by the assumption that the average cost per PM is constant and does not vary with the increase of $\lambda_{p}$.
Table 6: The minimal mean cost for various $C_{r}$.

\begin{tabular}{lcccc}
\hline$C_{r}$ & 100 & 200 & 300 & 400 \\
\hline$K^{*}$ & 1.8 & 1.8 & 1.8 & 1.8 \\
$L^{*}$ & 1.6 & 1.6 & 1.6 & 1.6 \\
$C\left(3, K^{*}, L^{*}\right)$ & 53.7591 & 78.5762 & 103.3932 & 128.2103 \\
\hline
\end{tabular}

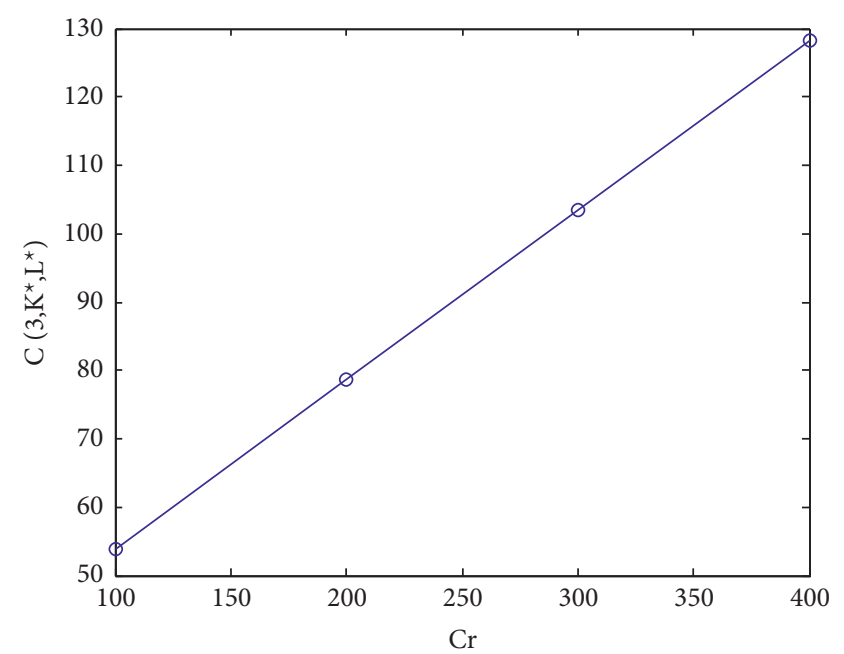

Figure 6: The minimal mean cost for various $C_{r}$.

TABLE 7: The minimal mean cost for various $\lambda$.

\begin{tabular}{lcccc}
\hline$\lambda$ & 0.25 & 0.55 & 0.85 & 1.15 \\
\hline$K^{*}$ & 1.6 & 1.8 & 1.8 & 1.8 \\
$L^{*}$ & 1.6 & 1.6 & 1.6 & 1.6 \\
$C\left(3, K^{*}, L^{*}\right)$ & 53.7052 & 78.5762 & 109.3083 & 135.6483 \\
\hline
\end{tabular}

TABle 8: The minimal mean cost for various $\lambda_{s}$.

\begin{tabular}{lcccc}
\hline$\lambda_{s}$ & 0.02 & 0.04 & 0.06 & 0.08 \\
\hline$K^{*}$ & 1.8 & 1.8 & 1.8 & 1.8 \\
$L^{*}$ & 1.6 & 1.6 & 1.6 & 1.6 \\
$C\left(3, K^{*}, L^{*}\right)$ & 78.5762 & 78.6994 & 78.8226 & 78.9458 \\
\hline
\end{tabular}

TABLE 9: The minimal mean cost for various $\lambda_{p}$.

\begin{tabular}{lccccc}
\hline$\lambda_{p}$ & 0.1 & 0.3 & 0.5 & 0.7 & 0.9 \\
\hline$K^{*}$ & 1.8 & 1.8 & 1.8 & 1.6 & 1.6 \\
$L^{*}$ & 1.6 & 1.6 & 1.6 & 1.6 & 1.6 \\
$C\left(3, K^{*}, L^{*}\right)$ & 80.4577 & 79.5170 & 78.5762 & 77.5985 & 76.5933 \\
\hline
\end{tabular}




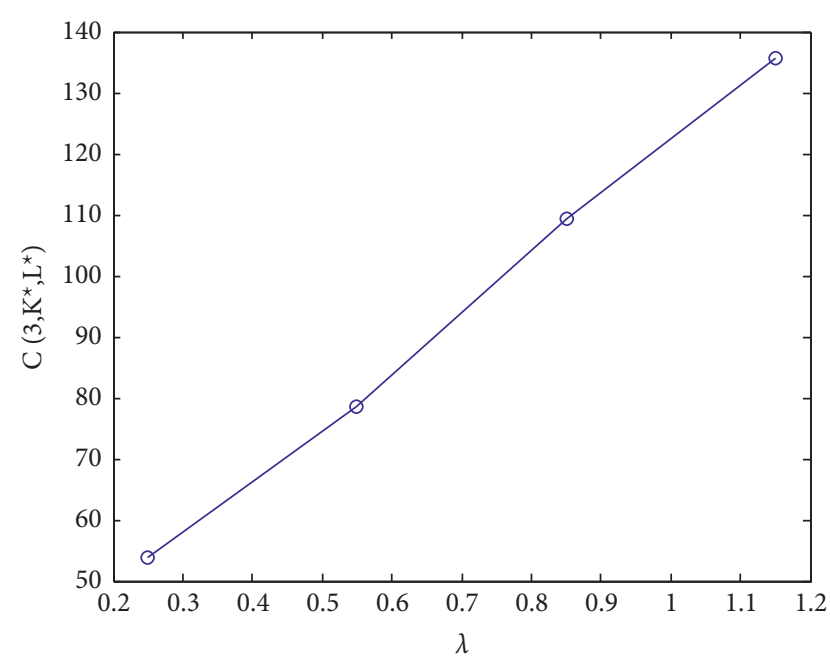

FIgUre 7: The minimal mean cost for various $\lambda$.

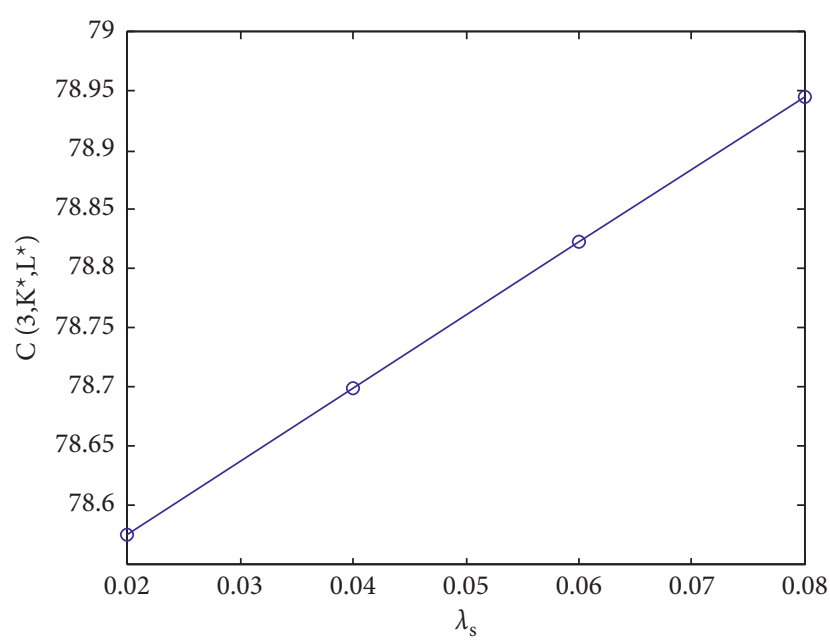

Figure 8: The minimal mean cost for various $\lambda_{s}$.

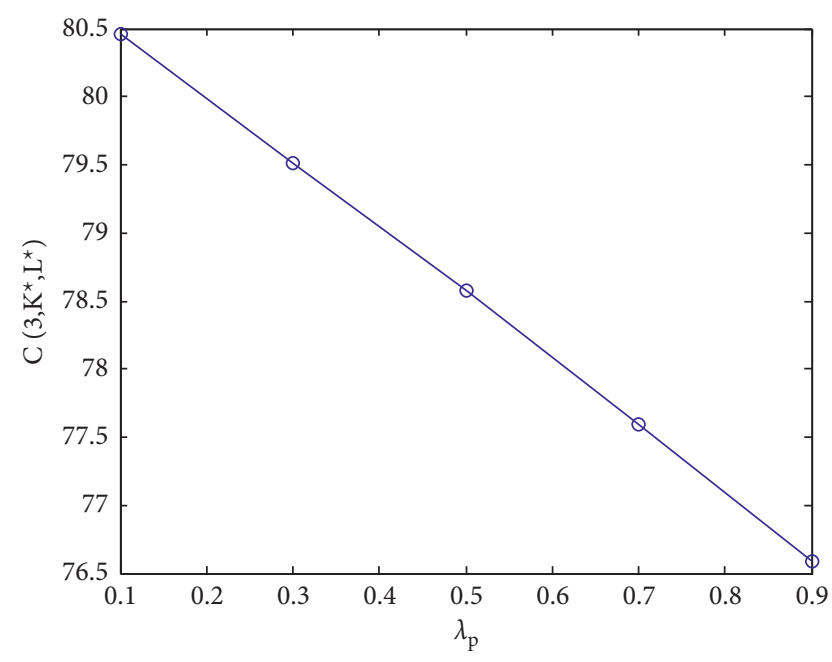

Figure 9: The minimal mean cost for various $\lambda_{p}$.

\section{Conclusions}

In the paper, the effect of external shocks on the degradation of products with nonrenewing and two-dimensional rectangle warranty service is considered. On each shock before the $N$ th one, either a failure of the product or an increase in product failure rate follows. The product is replaced by a new one on the Nth shock or after failures. A periodic 2D PM strategy, under which PM activities are scheduled every $K$ units of age or $L$ units of usage, whichever occurs first, is adopted over the warranty region. Under the assumption that shocks arrive according a homogenous Poisson process, the mean cost over the warranty region is obtained by using the renewal theory. Based on direct numerical RiemannStieltjes integration, an approximation algorithm of the cost is given. In the numerical example, the mean cost is minimized by the optimization of $2 \mathrm{D}$ preventive maintenance interval $(K, L)$ and the joint optimization of $(N, K, L)$.

The effects of model parameters such as cost of various maintenance actions, failure rates, the arrival rate of the shocks on the optimal warranty strategies, and the mean warranty cost are analyzed. The numerical example indicates that, for the fixed number of shocks before replacements $N=3$, the mean servicing cost increases with the increase of cost parameters, the arrival rate of shocks, and the raising in intensity function on a shock and decreases with the increases of the reduction in the intensity function after a PM action. Furthermore, the optimal 2D PM interval decreases with the increase of the minimal repair cost and the reduction in the product intensity function and increases with the increase of the cost of per PM and the arrival rate of shocks, whereas the cost of per replacement and the increase of product failure rate on shocks have little effects on the optimal 2D PM interval.

Customized and flexible warranty contracts are becoming widely popular recently. Combining them with the proposed $2 \mathrm{D}$ preventive maintenance warranty strategy considering external shocks is potential interest, furthermore, in the automobile warranty industry, customers usually insure against external shocks annually. Insurance companies, instead of manufacturers, bear the maintenance cost caused by external shocks, and they outsource the service to manufacturers. Hence, warranty decision-making analysis, based on the game theory of tripartite participation, will be another direction in future research.

\section{Data Availability}

The data used to support the findings of this study are included within the article.

\section{Conflicts of Interest}

The authors declare that they have no conflicts of interest.

\section{References}

[1] M. Shafiee and S. Chukova, "Maintenance models in warranty: a literature review," European Journal of Operational Research, vol. 229, pp. 561-572, 2013. 
[2] C. Kim, I. Djamaludin, and D. Murthy, "Warranty and discrete preventive maintenance," Reliability Engineering \& System Safety, vol. 4, no. 3, pp. 301-309, 2004.

[3] S. Wu and M. Zuo, "Linear and nonlinear preventive maintenance models," IEEE Transactions on Reliability, vol. 59, no. 1, pp. 242-249, 2010.

[4] H. Vahdani, S. Chukova, and H. Mahooji, "On optimal replacement-repair policy for multi-state deteriorating products under renewing free replacement warranty," Computers \& Mathematics with Applications, vol. 61, pp. 840-850, 2011.

[5] K. Jung, M. Park, and H. Dong, "Cost optimization model following extended renewing two-phase warranty," Computers \& Industrial Engineering, vol. 79, pp. 188-194, 2015.

[6] X. Wang, K. He, and Z. He, "Cost analysis of a piece-wise renewing free Replacement warranty policy," Computers \& Industrial Engineering, vol. 135, pp. 1047-1062, 2019a.

[7] R. Zheng and Y. Zhou, "Comparison of three preventive maintenance warranty policies for products deteriorating with age and a time-varying covariate," Reliability Engineering \& System Safety, vol. 213, Article ID 107676, 2021.

[8] J. Cha, M. Finkelstein, and G. Levitin, "Optimal warranty policy with inspection for heterogeneous, stochastically degrading items," European Journal of Operational Research, vol. 289, no. 3, pp. 1142-1152, 2021.

[9] T. Li, S. He, and X. Zhao, "Optimal warranty policy design for deteriorating products with random failure threshold," $R e$ liability Engineering \& System Safety, vol. 218, Article ID 108142, 2022.

[10] X. Wang and W. Xie, "Two-dimensional warranty: a literature review," Journal of Risk and Reliability, vol. 232, no. 3, pp. 284-307, 2018.

[11] Z. Cheng, Z. Yang, Y. Zhao, J. Wang, and W. Zhi, "Preventive maintenance strategy optimizing model under two-dimensional warranty policy," Eksploatacja i Niezawodnosc-Maintenance and Reliability, vol. 3, pp. 365-373, 2015.

[12] X. Wang and C. Su, "A two-dimensional preventive maintenance strategy for items sold with warranty," International Journal of Production Research, vol. 54, no. 19, pp. 5901-5915, 2016.

[13] C. Su and X. Wang, "A two-stage preventive maintenance optimization model incorporating two-dimensional extended warranty," Reliability Engineering \& System Safety, vol. 155, pp. 169-178, 2016.

[14] Y. Huang, C. Huang, and J. Ho, "A customized two-dimensional extended warranty with preventive maintenance," European Journal of Operational Research, vol. 257, no. 3, pp. 971-978, 2017.

[15] Y. Wang, Y. Liu, and A. Zhang, "Preventive maintenance optimization for repairable products considering two-dimensional warranty and customer satisfaction," Journal of Risk and Reliability, vol. 233, no. 4, pp. 553-566, $2019 \mathrm{~b}$.

[16] C. Su and L. Cheng, "Two-dimensional preventive maintenance optimum for equipment sold with availability-based warranty," Proceedings of the Institution of Mechanical Engineers-Part O: Journal of Risk and Reliability, vol. 233, no. 4, pp. 648-657, 2019.

[17] X. Wang, L. Li, and M. Xie, "An unpunctual preventive maintenance policy under two-dimensional warranty," European Journal of Operational Research, vol. 282, no. 1, pp. 304-318, 2020.

[18] N. C. Caballé, I. T. Castro, and C. J. Pérez, "A condition-based maintenance of a dependent degradation-threshold-shock model in a system with multiple degradation processes,"
Reliability Engineering \& System Safety, vol. 134, pp. 98-109, 2015.

[19] N. Caballe and I. Castro, "Analysis of the reliability and the maintenance cost for finite life cycle systems subject to degradation and shocks," Applied Mathematical Modelling, vol. 52, pp. 731-746, 2017.

[20] L. Yang, X. Ma, and Y. Zhao, "A condition-based maintenance model for a three-state system subject to degradation and environmental shocks," Computers \& Industrial Engineering, vol. 105, pp. 210-222, 2017.

[21] Q. Qiu and L. Cui, "Reliability evaluation based on a dependent two-stage failure process with competing failures," Applied Mathematical Modelling, vol. 64, pp. 699-712, 2018.

[22] Q. Guan, Y. Tang, and A. Xu, "Objective Bayesian analysis accelerated degradation test based on Wiener process models," Applied Mathematical Modelling, vol. 40, no. 4, pp. 2743-2755, 2015.

[23] Z. Pan and N. Balakrishnan, "Reliability modeling of degradation of products with multiple performance characteristics based on gamma processes," Reliability Engineering \& System Safety, vol. 96, no. 8, pp. 949-957, 2011.

[24] E. Keedy and Q. Feng, “A physics-of-failure based reliability and maintenance modeling framework for stent deployment and operation," Reliability Engineering \& System Safety, vol. 103, pp. 94-101, 2012.

[25] H. Peng, Q. Feng, and D. Coit, "Reliability and maintenance modeling for systems subject to multiple dependent competing failure processes," IIE Transactions, vol. 43, no. 1, pp. 12-22, 2010.

[26] K. Rafiee, Q. Feng, and D. Coit, "Condition-based maintenance for repairable deteriorating systems subject to a generalized mixed shock model," IEEE Transactions on Reliability, vol. 64, no. 4, pp. 1-11, 2015.

[27] W. Huang, J. Zhou, and J. Ning, "A condition based maintenance for system subject to competing failure due to degradation and shock," International Journal of Applied Mathematics, vol. 46, no. 2, pp. 223-230, 2016.

[28] S. Song, D. Coit, and Q. Feng, "Reliability analysis of multiplecomponent series systems subject to hard and soft failures with dependent shock effects," IIE Transactions, vol. 48, no. 8, pp. 720-735, 2016.

[29] S. Hao, J. Yang, and X. Ma, "Reliability modeling for mutually dependent competing failure processes due to degradation and random shocks," Applied Mathematical Modelling, vol. 51, pp. 232-249, 2017.

[30] K. Rafiee, Q. Feng, and D. Coit, "Reliability analysis and condition-based maintenance for failure processes with degradation-dependent hard failure threshold," Quality and Reliability Engineering International, vol. 33, no. 7, pp. 1351-1366, 2017.

[31] Z. Ye, D. Murthy, M. Xie, and L. Tang, "Optimal bum-in for repairable products sold with a two-dimensional warranty," IIE Transactions, vol. 45, no. 2, pp. 164-176, 2013.

[32] S. Wu, "Construction of asymmetric copulas and its application in two-dimensional reliability modelling," European Journal of Operational Research, vol. 238, no. 2, pp. 476-485, 2014.

[33] R. Jiang and D. Murthy, Maintenance: Decision Models for Management, Science Press, Beijing, 2008.

[34] M. Yu, Y. Tang, and W. Wu, "Optimal order-replacement policy for a phase-type geometric process model with extreme shocks," Applied Mathematical Modelling, vol. 38, no. 17-18, pp. 4323-4332, 2014. 
[35] D. Montoro-Cazorla and R. Pérez-Ocón, “A reliability system under cumulative shocks governed by a BMAP," Applied Mathematical Modelling, vol. 39, no. 23-24, pp. 7620-7629, 2015.

[36] S. Ross, Stochastic Processes, John, Wiely \& Sons, New York, NY, USA, 1983.

[37] M. Xie, "On the solution of renewal-type integral equations," Communications in Statistics-Simulation and Computation, vol. 18, no. 1, pp. 281-293, 1989. 